\title{
Emancipar-se do [projeto contraprodutivo de identificar o] espectador
}

Emancipating from the [counterproductive project of identifying the] spectator

\section{Marie-Madeleine Mervant-Roux \\ Tradução Sílvia Fernandes}

Marie-Madeleine Mervant-Roux

Diretora emérita de pesquisa do CNRS

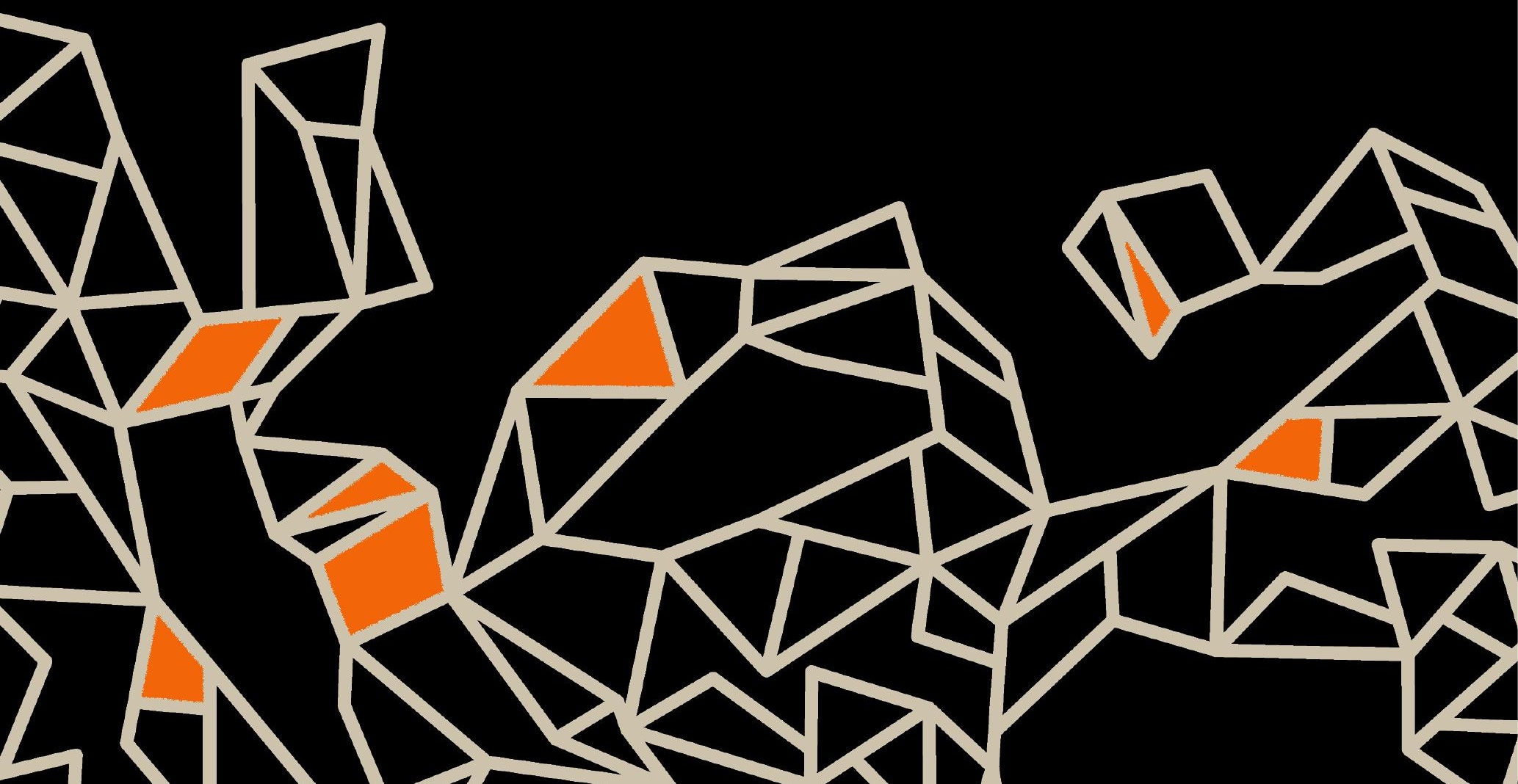




\section{Resumo}

Definir quem assiste ou quem assistiu a um espetáculo teatral como "espectador" é defini-lo do ponto de vista do teatro. O risco é esquecer que, para que o espetáculo seja mais que um espetáculo, o público deve encarnar, diante da cena, aquilo que na sociedade não é da esfera do teatro. Nem coautor, nem "emancipado" da estrutura original que funda a função dramática na cultura ocidental, aquele que vem de fora assume aí o estatuto exigente de intermediário entre dois mundos.

Palavras-chave: Espectador, Sociedade, Função dramática, Antropologia histórica.

\section{Abstract}

Defining who attends or who attended a theatrical spectacle as "spectator" is defining it from the point of view of the theater. The risk is to forget that, in order for the show to be more than a spectacle, the public must incarnate, in front of the scene, what in society does not belong to the sphere of theater. Neither co-author, nor "emancipated" from the original structure on which the dramatic function in Western culture is based, the one who comes from outside assumes the status of an intermediary between two worlds.

Keywords: Spectator, Society, Dramatic function, Historical anthropology.

Depois de dedicar quase dez anos de pesquisa de doutorado, de 1986 a 1996, ao espectador de teatro, e não ao público de teatro - a formulação de meu tema, no final dos anos 1980, testemunha a oficialização desse novo objeto teórico ${ }^{1}$-, e após uma década da defesa senti necessidade de escrever um texto² (MERVANT-ROUX, 2006) em que tentava analisar o desconforto que experimentava diante da importância que a figura do espectador rapidamente adquiriu nos estudos teatrais e o lugar crescente dedicado a essa figura nas programações dos teatros e dos festivais (mostrei sua notável ascensão e sua evolução nos textos programáticos do Festival de Avignon de 1947 a 2000).

1 A tese resultou na publicação L'Assise du théâtre. Pour une étude du spectateur (1998).

2 Foi abordado o teatro europeu, mais especificamente, o ocidental. 
De que forma poderia ser preocupante esse interesse geral e benevolente por aquilo que havia constituído meu objeto de estudo? Em que se baseava a sensação de ter favorecido, involuntariamente, um fenômeno prejudicial?

\section{Espectadores teatralizados}

A tese deu algumas respostas à questão que Denis Bablet, diretor do LARAS (Laboratório de Pesquisa sobre as Artes do Espetáculo), do CNRS, havia me proposto, e de que faço um rápido resumo: o espectador é, de fato, o "quarto criador" do espetáculo, como dizia Meyerhold, entre outros encenadores do século XX? Se é, como demonstrar isso com seriedade, cientificamente?

Como medir o efeito e a natureza exata da presença do espectador no acontecimento teatral? Interessar-se pelo espectador, e não pelo público, significava, segundo Denis Bablet, abandonar os métodos sociológicos (as pesquisas quantitativas) em proveito de outras abordagens que, de acordo com ele, não poderiam ser as da psicofisiologia (cujos limites já haviam sido testados) nem as da semiologia (em pleno desenvolvimento).

Ao adotar, de modo mais intuitivo que reflexivo, uma técnica etnográfica de pesquisa de campo, ao escolher voluntariamente um corpus de espetáculos em que o público, sentado e mudo, não deveria fazer mais nada a não ser olhar e escutar, ao observar as séries de representações dos espetáculos selecionados e desenvolver um protocolo para essas observações (incluindo o uso de questionários artesanais muito diferentes daqueles dos sociólogos), ao avançar lentamente, da descoberta à hipótese e da hipótese à verificação, pude finalmente descrever como as audiências sucessivas de um mesmo espetáculo, composições heterogêneas e mutantes de experiências íntimas, "ecoavam" o espetáculo, como elas especificavam e modulavam o que eu chamava de "sentido não dito" do espetáculo, sempre em suspensão, intervindo (a maior parte do tempo inconscientemente) sobre o ritmo, a tonalidade, a intensidade, quer dizer, sobre a matéria mesma da produção teatral.

Excepcionalmente "criador", às vezes destruidor, o conjunto de espectadores não pode deixar de agir sobre o que se passa em cena. Ao demonstrar, assim, a função modesta, mas decisiva, do espectador no breve tempo de 
ocorrência de cada espetáculo pude contribuir para a gestação do monstro teórico que eu via crescer: o "espectador-ator" ou "espectator".

O caráter monstruoso dessa criatura, que poderia tomar diferentes formas, vinha do fato de que ela parecia pertencer ao espetáculo de modo orgânico e, mais amplamente, ao universo teatral. Esse caráter, que despertava grande entusiasmo e se adequava às novas formas de criação (na verdade muito antigas, próximas da festa e do ritual) me parecia incompatível com a estrutura básica do teatro, como a antropologia histórica a concebia ${ }^{3}$ e como eu a havia abordado em minha pesquisa: as criações mais potentes eram obra de artistas que estabeleciam entre o palco e a plateia uma barreira intransponível e deixavam clara essa preferência ${ }^{4}$. E onde atores e espectadores misturam-se, a barreira só é maior. A nova reflexão cobriria, portanto, a história das "figurações" do espectador de teatro a partir dos anos 1950, período em que este se tornou um protagonista oficial do pensamento teatral, o que, convém enfatizar, imediatamente levantou questões ${ }^{5}$.

No final dos anos 1980, as figurações teóricas do espectador dividiam-se entre as que afirmavam sua autonomia em relação ao teatro - o "visitante da noite" mencionado por François Regnault (1986, p. 170) - e as que o tornavam um outro protagonista do teatro - o "jogador em potencial", de Denis Guénoun (1997). Estas claramente superaram as primeiras - no campo da mídia, pelo menos.

No início dos anos 2000, vários encenadores criaram imagens animalescas do público, oferecendo sua própria interpretação do que havia se tornado uma crise da condição espectadora, observada por certos teóricos ${ }^{6}$. Os gigantescos coelhos negros, idênticos e sinistros, instalados por Romeo Castellucci nas poltronas do Hebbel Theater de Berlim, em 2003, são um pesadelo pós-humano, e o problema está na plateia. Podemos tirar de tudo isso uma

3 Ver, por exemplo, Élie Konigson (1994, p. 42-49).

4 "Em 1978, quando apresentamos A classe morta em Roma, o público gritava: 'Mas o que nós devemos fazer?'. Eu respondia: 'Nada'” (KANTOR apud MERVANT-ROUX, 1998, p. 8).

5 Jean Vilar, em 1950, afirmou: "A noção de espectador e de público é uma noção falsa, um tema impraticável, uma má abstração se não se coloca em causa, antes do autor, antes do ator, antes do organizador, a noção de sociedade" (apud VILLIERS, 1953, p. 109-115).

6 Denis Guénoun (1997): "II n'y a plus guère de place, dans les procédures de notre théâtre, pour l'instance du spectateur". O autor nota que os aprendizes de atores são legiões, mas que os espectadores se rarefazem. 
rápida conclusão: quanto mais se fala do espectador, menos ele existe no real. Diante dessa afirmação, há uma lei misteriosa que se deve tentar esclarecer ${ }^{7}$.

\section{Espectadores sem palco nem plateia}

Em 2008, a acolhida recebida pelo texto intitulado "O espectador emancipado", de Jacques Rancière, de certa forma um texto que partiu dessa crise, confirmou-me que abordar o teatro a partir da figura do espectador era uma boa ideia falsa (o artigo de Rancière respondia a uma ordem - a que era preciso resistir). O espectador, como disse Brook, "está lá e não está". Fixá-lo mata-o e mata a reflexão sobre tudo o que Ihe diz respeito. Com o "espectador emancipado", verifiquei que a questão da relação entre o espectador de teatro e o teatro podia ser muito mal colocada sem que ninguém, ou quase ninguém, se importasse, nem mesmo os especialistas. O problema não estava na posição adotada em relação à suposta ação (ou interação) do espectador. O filósofo atacava com vigor todos os programas (de Brecht ou Artaud) visando a tornar o público ativo. A falha desse texto é mais fundamental, e ao menos dois de seus pressupostos merecem ser examinados. O primeiro diz respeito ao elogio incondicional do famoso "mestre ignorante", modelo do encenador no artigo. Negar o valor da transmissão de conhecimentos é não apenas questionável, mas perigoso. Com certeza, é a própria estrutura da escola que é posta em questão - e o mesmo vale para o teatro. Isso que será confirmado pelo segundo pressuposto: pensar que se pode diluir a questão da assistência ao teatro na experiência das artes em geral8 é esquecer que a prática do jogo dramático ocupou e ocupa um lugar original na Europa, não na "sociedade", como se diz frequentemente, mas na instituição (aqui entendida como o processo que consiste em instituir) da própria sociedade. Élie Konigson mostrou que a "função dramática" era uma das três grandes funções que organizaria a formação da cidade e, mais amplamente, da sociedade eu-

7 O destaque do termo "espectador" me constrangeu desde a publicação de minha tese. Eu não queria que ele aparecesse no título da obra, mas ele me foi imposto - no subtítulo - pelo editor. O termo já "vendia." Quantas vezes ouvi mencionar L'Assise du spectateur.

8 No essencial, identificados no texto de Rancière referente às artes visuais, mesmo se encontra algumas referências às artes da linguagem: "Uma comunidade emancipada é uma comunidade de narradores e de tradutores" (RANCIĖRE, 2012, p. 29). 
ropeia, "junto às funções de troca e de legislação" (KONIGSON, 1993). Assim, cada um dos dois pressupostos ignora a abordagem histórica da cultura e a dimensão "institucional", no sentido em que a entende o historiador do direito Pierre Legendre:

Assim como o ser humano exige uma cena para viver - cena da realidade e cena da imaginação - e nela inscreve um discurso, ou seja, de acordo com a literalidade da etimologia [de skènè, cena, próxima de skotos, sombra] exige e traz em si o lugar de sombra e trevas que o separa do mundo, da mesma forma toda sociedade, para existir, transpõe e transcende um lugar lógico vazio fazendo dele o lugar de sombra e trevas que chamamos de cena, onde vai inscrever-se o equivalente de um roteiro, o discurso de imagens que carrega o funcionamento institucional. (LEGENDRE, 2001, p. 24)

Em se tratando de refletir sobre a posição geral do espectador de teatro (na versão ocidental dessa prática), o quadro da reflexão deve ser, portanto, a sociedade em que uma cena foi literalmente liberada, o que se tratou de uma transgressão pois, nessas condições, o estado de espectador - que deve aceitar o jogo ficcional apresentado a ele pelo ator - exige um esforço ${ }^{9}$, não tem nada de natural e é construído de forma lenta e difícil à medida que o teatro se constrói. É a ausência dessa dimensão, que os especialistas de teatro conhecem intuitivamente, que faz o artigo soar falso. Ao contrário dos discursos que fazem do espectador um componente do espetáculo, o artigo de Jacques Rancière mostra-o totalmente desancorado do espaço-tempo concreto do jogo.

Esse texto poderia ter despertado reservas por muitas outras razões. Ninguém pareceu perceber que o que o autor pretendia revelar (a posição "clássica" do espectador não é uma posição passiva) já havia sido dito e escrito muito melhor por diversos artistas-pensadores (de Jouvet a Castellucci) e por diversos teóricos do teatro (citarei apenas três: Bernard Dort, Georges Banu, Anne Ubersfeld), várias afirmações-chave da exposição (particularmente as referentes à cena moderna e contemporânea) eram indubitavelmente falsas ${ }^{10}$, e a proposição final era formulada de modo tão

9 A obra-testemunho recente de Pierre Notte intitula-se $O$ esforço de ser espectador.

10 Por exemplo, as formas "autoritárias", as dos criadores potentes (dos mestres "não ignorantes"), puderam emancipar espectadores, como nos dizem tantos testemunhos. 
vago que podia abarcar todas as formas de criação - "uma nova cena da igualdade em que performances heterogêneas traduzem-se umas nas outras" (LEGENDRE, 2001, p. 28). Nessas condições, o sucesso quase incondicional do texto faz pensar que o termo "espectador" funciona como um fetiche e que, então, convém trabalhar sobre objetos precisos (espetáculos e figurações ${ }^{11}$ ) e exercer uma crítica meticulosa dos instrumentos teóricos, confrontando-os com o mundo social real ${ }^{12}$.

\section{Uma figura intermediária}

Não há mundo real que esteja fora da arte. [...] Há pregas e dobras do tecido sensível comum em que se unem e desunem a política da estética e a estética da política. Não há real em si [...], o real é sempre o objeto de uma ficção. (RANCIÈRE, p. 83-84)

É verdade (essa questão foi trabalhada especialmente por Jean-Marie Schaeffer e Thomas Pavel), mas ao mesmo tempo é falso no que diz respeito ao teatro. A regra do teatro é que ele abre um espaço à parte na cidade, que não obedece às leis do espaço social comum. A aceitação dessa ficção instituinte é uma pedra de toque cultural: certas sociedades, em certos períodos, recusaram-na violentamente, aceitando apenas o rito associado à fé e aberto a fiéis, não a espectadores ${ }^{13}$.

A dificuldade, atualmente muito difundida, de aceitar essa regra primeira que, de acordo com alguns, leva ao escândalo e à desordem, dificuldade de que o islamismo radical oferece uma imagem ao mesmo tempo extrema e modernizada - da destruição do teatro de Palmira ao ataque assassino ao

11 Como no colóquio Portraits de spectateurs de théâtre: faire œuvre d'une réception (textes, images, films, spectacles), para o qual era preciso estudar a maneira como o espectador de teatro era representado em uma obra precisa (literária, pictural, cinematográfica...) (ABRECHT; MICHEL; PIOT, 2017). Ou o seminário NoThX, que procede a partir da análise de exemplos.

12 O que faz Myriam Revault d'Allonnes (2016), que, contra a abordagem platônica - do teatro e do espectador - defende, com sucesso, a abordagem aristotélica.

13 O antropólogo Jack Goody (2003[1997], p. 116 e capítulo 4) usa o termo "teatro" para designar um conjunto de "representações" (performances) muito variadas segundo as culturas, cujo ponto comum é que não destaque o rito. Em todos os casos, trata-se de "jogar" e não de "fazer". É nessa mesma acepção, pois a questão da distinção radical com o rito nos parece da maior importância, que utilizamos a palavra "teatro". 
teatro do Bataclan -, mostra que a posição de espectador do jogo dramático nunca é um dado, mas deve reconstruir-se constantemente.

A exposição que fizemos acerca do filme L'Esquive ( $A$ evasão), por ocasião do colóquio Retratos de Espectadores, mostrava como, em 2004, Abdellatif Kechiche narrava uma gênese do teatro na qual o teatro não existe (na verdade, não há um lugar teatral na cidade de sua ficção - nem naquela em que filmou: os Franc-Moisins em Saint-Denis, subúrbio leste de Paris), mas em que há espécies de prototeatros. Nos espaços urbanos - a sala de aula, o salão de festas e o anfiteatro ao ar livre - e nas práticas sociais - exercícios escolares das aulas de francês, jogos amadores entre amigos -, as meninas desempenham papel importante por meio dos quais se dá - e o cineasta captou isso - a aprendizagem de um olhar e de uma escuta de espectador sem que isso nunca seja formulado enquanto tal. Esse olhar não é catalogado (MERVANT-ROUX, 2017).

Para que a função dramática possa se exercer, é necessário um intermediário, um mediador do teatro fora do teatro, um mediador do mundo exterior no interior do teatro, que conheça suficientemente o teatro, sem no entanto estar integrado à máquina teatral. Como chegar a esse equilíbrio? Como pensar uma educação no teatro que não seja nem uma mediação cultural edulcorante, nem um convite para participar da cena? Que torne o teatro desejável enquanto fortalece o partido do real? Uma das forças do filme de Abdellatif Kechiche é nos lembrar que uma rede antropológica fina e complexa constitui, há muito tempo, o espaço invisível de uma tal educação: da declamação de poemas na escola aos seriados radiofônicos e teatros musicais, das festas à fantasia aos espetáculos de amadores. Essas formas desapareceram sem que muitas outras as substituíssem. Note-se que todas elas estavam fora do teatro, cheias de teatro e exteriores ao teatro.

No período em que escrevia minha tese, notei que, cada vez com maior frequência, outras atividades entravam nos espaços teatrais - café, restaurante, livraria - quando antes se desenvolviam nas imediações do edifício teatral, ruas e praças vizinhas, ou cruzamentos que levavam a ele. Como o teatro não estava mais realmente na cidade, era ele que acolhia a cidade. Atualmente a desvalorização generalizada, nas esferas da arte, do teatro feito por amadores e da aprendizagem escolar do jogo, a rejeição, por setores inteiros do campo teatral e teatrológico, daquilo que fazia parte da cultura teatral no sentido amplo (a poesia declamada, a leitura em voz alta, a canção, a ficção áudio ou audiovisual) parece despertar, em determinados criadores 
e profissionais, a responsabilidade de gestão dessas formas nas instituições teatrais - com as dimensões criativas que se seguem, mas também com o risco de um novo desequilíbrio entre a cena e o real, e a necessidade, sempre, de matrizes exteriores para produzir aqueles que o teatro chamará "espectadores" - e deverá fazê-lo com cuidado.

\section{Referências bibliográficas}

ABRECHT, D.; MICHEL, L.; PIOT, C. Portraits de spectateurs de théâtre: faire œuvre d'une réception (textes, images, films, spectacles). Montpellier: L'Entretemps, 2017.

D’ALLONNES, M. R. Le miroir et la scène. Ce que peut la représentation politique. Paris: Seuil, 2016.

GUÉNOUN, D. Le théâtre est-il nécessaire? Circé, Penser le théâtre, p. 166, 1997.

Edição em português $\mathbf{O}$ teatro é necessário?. Trad. Fatima Saadi. São Paulo: Perspectiva/Debates, 2004.

GOODY, J. La peur des représentations. L'ambivalence à l'égard des images, du théâtre, de la fiction, des reliques et de la sexualité. Paris: La Découverte, 2003[1997].

KONIGSON, E. Diviser pour jouer. Les Cahiers de la Comédie-Française, Paris, n. 11, p. 42-49, 1994.

.Traditions et lisières. Un art urbain au pied du mur, Marseille, Lieux publics, p. 14-17, 1993.

LEGENDRE, P. De la Société comme Texte. Linéaments d'une anthropologie dogmatique. Paris: Fayard, 2001.

MERVANT-ROUX, M-M. On va dire que le public, il est là. In: ABRECHT, D.; MICHEL,

L.; PIOT, C. Portraits de spectateurs de théâtre: faire œuvre d'une réception (textes, images, films, spectacles). Montpellier: L'Entretemps, 2017.

Figurations du spectateur. Paris: L'Harmattan/Univers théâtral, 2006.

L’Assise du théâtre. Pour une étude du spectateur. Paris: CNRS Éditions, 1998.

NOTTE, P. L'effort d'être spectateur. Besançon: Les Solitaires intempestifs, 2016.

RANCIĖRE, J. O espectador emancipado. São Paulo: Martins Fontes, 2012.

REGNAULT, F. Le visiteur du soir. In: REGNAULT, F. Le spectateur. Paris: BEBA;

Nanterre-Amandiers: Théâtre National de Chaillot, 1986.

VILLIERS, A. Du spectateur et du public. In: Théâtre et collectivité. Paris: Flammarion, 1953.

Recebido em 21/05/2017

Aprovado em 22/05/2017

Publicado em 17/07/2017 